\title{
La falta del registro de nacimiento y la vulneración de los derechos humanos
}

\author{
Carlos Alejandro Ledesma-Lois ${ }^{*}$ \\ Alina Nettel-Barrera ${ }^{* *}$ \\ Florencia Aurora Ledesma-Lois ${ }^{* * *}$
}

\footnotetext{
* Especialidad en Derecho Notarial, Licenciado en Derecho, Universidad Autónoma de Querétaro, México. Correo electrónico: carlos.ledesmalois@notaria9qro.mx

** Doctora en Derecho. Profesora, Universidad Autónoma de Querétaro, México.

Correo electrónico: alina.nettel@uaq.mx

*** Especialización en Derecho Notarial, Licenciada en Derecho, Universidad Autónoma de Querétaro, México. Correo electrónico:

fa.ledesmalois@notaria9qro.mx
}

Recibido: 13 de octubre del 2016 Aprobado: 30 de noviembre del 2016

Cómo citar este artículo: Carlos Alejandro Ledesma-Lois, Alina Nettel-Barrera y Florencia Aurora Ledesma-Lois. La falta del registro de nacimiento y la vulneración de los derechos humanos. DIXI 25. Enero 2017. Pág. 9. doi: http://dx.doi.org/10.16925/ di.v19i25.1816

\section{Resumen}

Introducción: en la actualidad, en el territorio de los Estados Unidos Mexicanos, existe una cantidad no precisa de seres humanos cuyo nacimiento nunca ha sido registrado, lo que acarrea diversas consecuencias negativas para el ejercicio de sus derechos y repercute en tres dimensiones distintas: la dimensión fáctica, al existir una negativa de servicios que proporciona el Estado, entre otros, el acceso a la salud, a que se le administre justicia por parte de los tribunales o a la participación en programas de seguridad social y educación. También se relaciona con una dimensión axiológica, ya que materialmente se excluye al ser humano de la sociedad privándolos de la seguridad jurídica que ampara a quienes tienen la posibilidad de identificarse y, por último, la normativa al negarse la posibilidad de ser sujetos reconocidos por el Estado. Metodología: el problema de investigación se aborda desde el método del realismo jurídico, a partir del análisis de los fenómenos que están presentes en el objeto de estudio y su explicación, en relación con las consecuencias sociológicas, económicas y jurídicas. Resultados: en conformidad con las cifras que se exponen, en nuestro país se estima que hay alrededor de 10 millones de seres humanos cuyo nacimiento nunca ha sido registrado, por lo que no tienen acceso a servicios de salud, educación, justicia, esparcimiento y libre desarrollo integral. Conclusiones: la tutela de los derechos humanos queda seriamente comprometida por la falta de registro de nacimiento. En esta medida, las personas no son materialmente existentes para el Estado y les está vedado el ejercicio de derechos esenciales que les permitan desarrollar una vida digna.

Palabras clave: derechos humanos, dignidad, identidad, nombre, registro de nacimiento, ser humano. 


\title{
Lack of birth certificate and violation of human rights
}

\begin{abstract}
Introduction: at present, in the territory of the United Mexican States, there is an imprecise number of human beings whose birth has never been recorded, which leads to several negative consequences for the exercise of their rights and has an effect on three different dimensions: A factual dimension, as the State denies services such as access to healthcare, administration of justice by courts, or participation in social security and education programs; an axiological dimension, since the human being is materially excluded from society, depriving them of the legal security that covers those who can identify themselves; and, lastly, a regulatory dimension, when individuals are denied recognition by the State. Methodology: the research problem is approached from the legal realism method, based on the analysis of phenomena that are present in object of study and its explanation, in relation to the sociological, economic, and legal consequences. Results: according to the figures presented, it is estimated that in our country there are around 10 million human beings whose birth has never been recorded, so they do not have access to healthcare, education, justice, recreation and free comprehensive development. Conclusions: the protection of human rights is seriously compromised by the lack of a birth certificate. In this sense, individuals are materially inexistent to the State and are denied the exercise of rights essential to live a decent life.
\end{abstract}

Keywords: human rights, dignity, identity, name, birth certificate, human being.

\section{A falta da certidão de nascimento e a violação dos direitos humanos}

\section{Resumo}

Introdução: na atualidade, no território dos Estados Unidos Mexicanos, existe uma quantidade não exata de seres humanos cujo nascimento nunca foi registrado, o que acarreta diversas consequências negativas para o exercício de seus direitos e repercute em três dimensões diferentes: a dimensão fática, ao existir uma negativa de serviços que o Estado proporciona, como o acesso à saúde, a administração da justiça por parte dos tribunais ou a participação em programas de segurança social e a educação. Também se relaciona com uma dimensão axiológica, já que materialmente se exclui o ser humano da sociedade ao privá-los da segurança jurídica que ampara quem tem a possibilidade de se identificar; por último, a normativa, ao se negar a possibilidade de serem sujeitos reconhecidos pelo Estado. Metodologia: o problema de pesquisa é abordado a partir do método do realismo jurídico por meio da análise dos fenômenos que estão presentes no objeto de estudo e em sua explicação, com relação às consequências sociológicas, econômicas e jurídicas. Resultados: de acordo com as cifras expostas, em nosso país, estima-se que há ao redor de dez milhões de seres humanos cujo nascimento nunca foi registrado, razão pela qual não têm acesso a serviços de saúde, educação, justiça, lazer e livre desenvolvimento integral. Conclusões: a tutela dos direitos humanos fica seriamente comprometida pela falta de certidão de nascimento. Nesse sentido, as pessoas não são materialmente existentes para o Estado e lhes está vedado o exercício de direitos essenciais para desenvolver uma vida digna.

Palavras-chave: direitos humanos, dignidade, identidade, nome, certidão de nascimento, ser humano. 


\section{INTRODUCCIÓN}

Los atributos de la persona son reconocidos a través del registro de nacimiento, instrumento jurídico por el cual el Estado asienta el nacimiento de un individuo y le hace partícipe de la vida jurídica. La falta de registro de nacimiento inhabilita los mecanismos de protección que aseguran el desarrollo de la vida en sociedad, ya que el Estado no los considera jurídicamente. Actualmente, en los Estados Unidos Mexicanos no se cuenta con cifras precisas con relación a cuántos nacimientos de seres humanos no han sido registrados, por lo tanto, se conoce solo de manera parcial cuánta población ha nacido en el territorio mexicano en virtud de los censos que ha practicado el Instituto Nacional de Estadística y Geografía.

El Censo Nacional de Población y Vivienda llevado a cabo por dicho instituto en el 2012 arrojó un total de nacimientos registrados por entidad federativa en la residencia habitual de la madre -incluyendo los nacimientos ocurridos en el extranjero- de $2498,880,{ }^{1}$ mientras que en el 2013 se registró un total de nacimientos de $2478,889 .{ }^{2}$

En el 2014 se registró un total de nacimientos de 2463,420 , y, de acuerdo con la última actualización realizada en febrero del 2016, en el 2015 la tasa bruta registrada de natalidad se redujo al $18,5 \%,{ }^{3}$ de la que se colige que cada vez existen más seres humanos en el país.

Se estima que en México hay alrededor de 10 millones de seres humanos, cuyo nacimiento nunca ha sido registrado, según lo indicó la diputada Joann Novoa, como consta en el boletín de la Cámara de Diputados número 5199, de fecha 27 de mayo de 2012; por ende, no se ha certificado el nacimiento de aquéllos niños, al no haberse levantado un acta al respecto en alguna oficialía del registro civil, documento que

1. Véase INEgi. NATALIDAD. NACIMIENTOS REgISTRAdos POR ENTI DAD FEDERATIVA DE RESIDENCIA HABITUAL DE LA MADRE SEGÚN SEXO, 2012 A 2014. Disponible en http://www3.inegi.org.mx/sistemas/sisept $/$ Default.aspx $? \mathrm{t}=$ mdemo23\&s=est $\& \mathrm{c}=17526$

2. Véase inegi. Natalidad. NACIMIEntos Registrados SEgúN SEXo, 1990 A 2014. Disponible en http://www3.inegi.org.mx/sistemas $/$ sisept $/$ Default.aspx? $t=$ mdemo22\&s $=$ est $\& c=17525$

3. Véase inegi. Natalidad. TASA BRUtA DE NATAlidAd, 1990 A 2015. Disponible en http://www3.inegi.org.mx/sistemas/sisept/ Default.aspx $? \mathrm{t}=\mathrm{mdemo} 14 \& \mathrm{~s}=\mathrm{est} \& \mathrm{c}=17533$

4. Joann Novoa. Sin acta de nacimiento, 10 millones de mexicanos. BOLETÍN DE LA CÁMARA DE DIPUTADOS DE H. CONGRESO DE LA UNIÓN 5199. Mayo 27 del 2012. Disponible en http://www3.diputados. gob.mx/camara/005_comunicacion/a_boletines/2012_2012/005 mayo/27_27/5199_sin_acta_de_nacimiento_10_millones_de mexicanos_no_puede_ser_esto_en_pleno_siglo_xxi_diputada_ joann_novoa les serviría para acreditar cómo se llaman, cuándo nacieron, quiénes son sus padres y de qué lugar son.

Como se expondrá en el presente artículo, existe discrepancia entre la realidad y la normatividad vigente que pretende salvaguardar los derechos humanos, ${ }^{5}$ en la medida en que las previsiones legales sobre la eficiencia de los registros civiles quedan desvirtuados frente a la gran cantidad de personas que, se estima, no tienen la posibilidad de acreditar su propio nacimiento.

La temática es de gran relevancia si se tiene en cuenta que, tras la reforma constitucional en materia de derechos humanos del 2011, establecida en el artículo 1, tercer párrafo, todas las autoridades en el ámbito de su competencia tienen la obligación de promover, respetar, proteger y garantizar los derechos humanos, por lo que estas deben prevenir, investigar, sancionar y reparar las violaciones que se hagan a dichos derechos.

Este panorama permite posicionarse desde una perspectiva crítica sobre la ineficacia del sistema de gestión de los registros civiles, lo que se constituye como el objetivo general al que deben sumarse otros fines, como son: analizar la eficacia de la reforma constitucional del 2014 en el artículo 4, octavo párrafo, respecto a la gratuidad de la primera constancia del registro de nacimiento; y estudiar la viabilidad de los requisitos de registro y las condiciones socioeconómicas de las personas más vulnerables, así como el análisis sobre la actuación debida de las administraciones competentes para registrar, en relación con la garantía del derecho a la identidad. En el desarrollo de los objetivos, el artículo aborda el marco conceptual y legal del ser humano en el ámbito jurídico, las reformas a la Constitución de los Estados Unidos Mexicanos en la materia, las dimensiones del problema y sus puntos de inflexión.

La problemática se aborda desde una metodología realista, ya que aporta elementos metodológicos coherentes con el fenómeno de estudio, es decir, las graves consecuencias en el desarrollo de la vida de los seres humanos que no cuentan con el registro de su

\footnotetext{
5. Véase Eleonora Parra de Párraga. La inhumanidad de los derechos humanos. A la saga de los derechos humanos. Razón y PALABRA. Pág. 4. Disponible en http://www.razonypalabra.org.mx/N/ N81/M81/ 03_Parra_M81.pdf: "Es, pues, un contraste abismal entre la teoría y la práctica, entre el derecho y la vida cotidiana, el cual solo mediante la gestión de aparatos estatales y de los organismos internacionales, aunado a la participación ciudadana y sus movimientos sociales y partidos políticos a nivel local, nacional o mundial, con el propósito de ver hechos realidad las promesas contenidas en las declaraciones y convenciones internacionales y locales en materia de derechos humanos".
} 
nacimiento. Este método facilita desarrollar la investigación en consideración de los elementos sociológicos, económicos y jurídicos involucrados.

\section{ASPECTOS FUNDAMENTALES SOBRE EL}

\section{HOMBRE, EL SER HUMANO Y LA PERSONA EN EL ÁMBITO JURÍDICO}

Como se presenta en el capítulo siguiente, en el artículo 4, octavo párrafo, de la Constitución Política de los Estados Unidos Mexicanos, se llevó a cabo una reforma en el 2014, por la que se estableció que toda persona tiene derecho a la identidad y a ser registrado de manera inmediata desde su nacimiento, tras lo cual, la autoridad competente debe expedir de manera gratuita la primera copia certificada del acta de nacimiento. La intención del Constituyente Permanente no es suficiente para resolver el problema, pues la falta de presencia de los órganos gubernamentales en algunas comunidades dificulta el registro para personas que deben invertir más de lo que tienen con el fin de trasladarse a las oficinas del Registro Civil más cercano. Por otra parte, debe considerarse que, para muchos otros mexicanos, la falta de acta de nacimiento es algo habitual generación tras generación, especialmente, en las comunidades indígenas o en el caso de la gente que vive en las calles.

La primera sala de la Suprema Corte de Justicia de la Nación, en una tesis aislada, expone que el objetivo de la reforma al artículo 4 de la Constitución se realizó a fin de reconocer, como derechos constitucionales, todos los derechos de los niños establecidos en tratados internacionales de los que nuestro país forma parte. ${ }^{6} \mathrm{El}$ registro de nacimiento, en estos términos, se constituye como la vía para la concreción de los derechos de los niños, de ahí la importancia de tratar adecuadamente a los órganos encargados de dicho registro y de facilitar económicamente su obtención.

En el ámbito internacional, el artículo 6 de la Declaración Universal de los Derechos Humanos de $1948{ }^{7}$ señala que los seres humanos tienen derecho al reconocimiento de su personalidad jurídica, siendo este correlativo con el artículo 16 del Pacto

6. Véase Suprema Corte de Justicia de la Nación. Primera Sala, Novena Época, Tomo Xxxiv. Tesis AIsLADA. 1ª. CXvi/20011. Registro 161100. Semanario Judicial de la Federación y su Gaceta. (Septiembre de 2011).

7. Cf. Declaración Universal de los Derechos Humanos de 1948
Internacional de Derechos Civiles y Políticos de 1966, al establecer exactamente el mismo texto normativo: "Todo ser humano tiene derecho, en todas partes, al reconocimiento de su personalidad jurídica". Se resalta así la importancia de que todo ser humano sea reconocido por el derecho y tenga la posibilidad de gozar de sus derechos, independientemente del lugar en donde se encuentre.

Asimismo, de acuerdo con el artículo 1 de la citada Declaración Universal de los Derechos Humanos de 1948, se hace hincapié en que todos los seres humanos, desde su nacimiento, son libres e iguales en dignidad humana y derechos. En este sentido, en la Convención Americana sobre Derechos Humanos de 1969, se encuentra dispuesto que para efectos de dicha convención, se entenderá por persona a todo ser humano, quien, conforme al artículo 18, tiene derecho a un nombre propio y a los apellidos de sus padres o al de uno de ellos, y a que la ley reglamente la forma de asegurar tal derecho, incluso utilizando nombres supuestos. Lo anterior es difícil en México, ya que, como se verá más adelante, el trámite de registro es complejo.

La importancia de clarificar en materia jurídica el concepto de ser humano en relación con el significado de persona es trascendental, porque está íntimamente relacionado con el tipo de protección que el Estado configura para sus habitantes, y permite hacer cuestionamientos tales como: ¿Qué entendemos por hombre, por ser humano y por persona? ¿Cuáles son los atributos de la persona? ¿Cómo se vincularía el concepto de persona en el derecho interno a los tratados internacionales? Estas preguntas de investigación deben abordarse desde un posicionamiento filosófico y epistemológico, con el propósito de lograr identificar el modelo seguido por el ordenamiento y los estándares de adecuación a los criterios internacionales. Es por ello que, entre otros autores, Morin, en su ensayo "La Unidualidad del hombre", señala:

La idea de la unidad del hombre se afianzó y afirmó en y por el humanismo. El humanismo funda al hombre aislándolo de la naturaleza y autonomizándolo en el derecho; el hombre es autosuficiente y adquiere su legitimidad y su fundamento en la (su) Razón: homo sapiens quizás surgió de la naturaleza, pero, por su

\footnotetext{
8. Véase Rafael Hernández Marín. Sujetos Jurídicos, Capacidad Jurídica y Personalidad Jurídica. REVISTA DE FUNDAMENTACIÓN DE LAS INSTITUCIONES JURÍDICAS Y DE DERECHOS HUMANOS 36. 1997. Pág. 118: "Un individuo es o no persona (jurídica), en términos absolutos; y será persona (jurídica) o no, según sea o no calificado como persona (jurídica) por alguna regla jurídica”.
} 
sapiencia, escapa a esta naturaleza. El hombre es el ser supremo, superior, y, por eso mismo, debe ser respetado y honrado en todo hombre. De ahí esa idea humanista universalista y emancipadora: la idea de los derechos del hombre. ${ }^{9}$

Resulta trascendente mencionar el humanismo, ya que tal corriente filosófica conlleva una actitud antropocéntrica, al exaltar la figura del hombre y considerarlo como el centro del pensamiento y la vida misma, apreciando su supremacía sobre todo lo demás creado en el mundo, y dando lugar a los derechos humanos para salvaguardar sus intereses.

Por otra parte, sobre la definición de ser humano, Koffman considera que se trata de un ser biológico, emocional, que se estructura en la intersubjetividad, oscila permanentemente entre la búsqueda de la autonomía y la dependencia de los otros, constructor de conocimientos, lingüístico, histórico y culturalmente construido y extremadamente frágil; agrega que el ser humano es todo esto funcionando en simultáneo. ${ }^{10}$ Lo anterior es importante, ya que dicho concepto se estudia de manera transdisciplinar, particularmente desde el área de la psicología, e identifica las características físicas e intelectuales que distingue al hombre como ser humano de los demás animales, siendo la característica principal el raciocinio que le permite construir conocimientos, utilizar un lenguaje y crear la historia.

Respecto al concepto de persona, es indispensable citar a Kelsen, ya que su paradigma positivista continúa imperando en el derecho mexicano:

El concepto de persona física o natural no es otra cosa que la personificación de un complejo de normas jurídicas. El hombre, como hombre individualmente determinado es solo el elemento que constituye la unidad en la pluralidad de esas normas (...) Que la afirmación consistente en que "la persona física o natural es un ser humano" es incorrecta, resulta obvio cuando se considera que lo que es verdad en relación con el ser humano de quien se dice que es persona, de ninguna manera es siempre verdadero en relación con la persona. El aserto de que un ser humano tiene deberes y

9. Véase Edgar Morín. La unidualidad del hombre. GAZETA DE Antropología. 1997. Disponible en http:/www.ugr.es/ pwlac/ G13_01Edgar_Morin.html

10. Véase RaúlG Koffman.¿Quées un serhumano?Revista MÉDICA DE Rosario 74. 2008. Págs. 32-34. Disponible en http://www.circulomedicorosario.org/Upload/Directos/Revista/960256Ra\%C3\%BAl\%20 Koff man.pdf derechos significa que las normas jurídicas regulan la condición de este en una forma específica. ${ }^{11}$

Puede observarse que Kelsen distingue el complejo concepto de persona, entendiéndolo entonces como aquella personificación de normas jurídicas por medio de las cuales se regulan los derechos y deberes del ser humano, de modo que minimiza al hombre al considerarlo únicamente como un elemento sobre el cual recaen las normas jurídicas, por lo que, a pesar de los esfuerzos por reconocer la importancia del ser humano, en nuestro país este no es nadie sin personalidad jurídica.

Por otra parte, resulta necesario volver al plano normativo internacional, con el fin de mencionar la trascendencia que conlleva que un ser humano, desde niño, sea inscripto para que goce desde el principio de los atributos de la persona. Esto se señala en el artículo 7 de la Convención sobre los Derechos del Niño, publicada en el Diario Oficial de la Federación en 1991, de la que México forma parte: "El niño debe ser inscripto inmediatamente después de su nacimiento y éste tendrá derecho desde que nace a un nombre, a adquirir una nacionalidad y en la medida de lo posible, a conocer a sus padres y a ser cuidado por ellos.".

11. Véase Hans Kelsen. Teoría general del derecho y deI Estado. unAm. (1969). Pág. 112.

12. Véase Tribunales Colegiados de Circuito. Tesis: Aislada. Civil I.3o.C.979 C. Registro: 161495. Semanario Judicial de la Federación y su Gaceta, Novena Época, Tomo xxxıv, Pág. 2189. (Julio de 2011)

"RECONOCIMIENTO DE HIJO. ACTA DE NACIMIENTO EXPEDIDA POR EL JUEZ DEL REGISTRO CIVIL, SURTE TODOS SUS EFECTOS HASTA QUE NO SE DEClare SU NUlidad JUdicialmente.- De conformidad con el artículo 50 del Código Civil para el Distrito Federal, las actas extendidas por el Registro Civil hacen prueba plena en todo lo que el Juez del Registro Civil, en el desempeño de sus funciones da testimonio de haber pasado en su presencia, sin perjuicio de que el acta pueda ser redargüida de falsa. Por otra parte, de la interpretación sistemática de lo dispuesto por los diversos $340,344,345,352,353$, $366,367,369$ y 389 de la legislación en comento, se desprende que el acto jurídico de reconocimiento de hijo, constituye una manifestación de voluntad en virtud de la cual se imponen a quien lo realiza todas las obligaciones que derivan del parentesco. Así, al ser un acto puramente volitivo, éste no puede ser revocado por quien lo hizo, ni basta el dicho de la madre para excluir esa paternidad. De ahí que, de acuerdo a los preceptos citados la única forma de revocar dicho acto para que el reconocido pierda la condición de hijo de quien lo reconoció, es mediante declaración judicial, en la que se declare su nulidad. Entonces, aun cuando en juicio se demuestre la existencia de dos actas de nacimiento en las que se haya reconocido como hijo a la misma persona por diferentes padres, en diferentes épocas, si no existe constancia de que se haya declarado judicialmente la nulidad de alguna de ellas, ambas continúan vigentes y subsisten en sus efectos legales". 
Tal precepto destaca que el registro de nacimiento de un menor es imprescindible para que este sea reconocido en el ámbito jurídico y pueda hacer uso de sus derechos, pero, además, cabe señalar que al contar con personalidad jurídica, el menor tendrá acceso a los servicios que proporciona el Estado y así logrará satisfacer sus necesidades básicas, lo que se relaciona con el "derecho mínimo vital", del cual deben gozar todos los seres humanos. El derecho mínimo vital es aquel por el que el Estado tiene la obligación de garantizar que todos sus habitantes se alleguen de aquellos elementos necesarios para tener una calidad de vida digna y decorosa, establecidos en la Declaración Americana de los Derechos y Deberes del Hombre de 1948, artículo 17: “Toda persona tiene derecho a que se le reconozca en cualquier parte como sujeto de derechos y obligaciones, y a gozar de los derechos civiles fundamentales", ${ }^{13}$ siendo estos el derecho a la preservación de la salud y el bienestar, el derecho a la nacionalidad, el derecho a la cultura, el derecho a la educación, ${ }^{14}$ el derecho al acceso a la justicia, el derecho al trabajo y a la justa retribución, entre otros.

En este sentido, existe una tesis aislada, emitida por la Primera Sala de la Suprema Corte de Justicia, en la que se expone, cuando menos, dos situaciones originadas del registro: la satisfacción de necesidades a través de la prestación de servicios públicos, y la exigibilidad de los derechos que corresponden a la protección de los menores con respecto a los ascendientes. ${ }^{15}$

\footnotetext{
13. Véase Declaración Americana de los Derechos y Deberes DEL HOMBRE 1948.

14. Imanol de la Flor. El ACTA DE NACimiento MEXICANA COMO VEHÍCULO PARA EJERCER EL DERECHO A LA EDUCACIÓN; CASO DF LOS HIJOS DE MIGRANTES EN RETORNO. REVISTAS JURÍDICAS, UNAM. Pág 487. Disponible en http:// revistas.juridicas.unam.mx/ index. php/derecho-internacional/article/view/436/697

En otros términos, lo que se significa es que mediante la aplicación de medidas oportunas por parte del Estado, haciendo uso de su facultad estatal, específicamente a través del registro de nacimiento como acto administrativo, se facilitaría la garantía del derecho a la educación.

15. Suprema Corte de Justicia. Primera Sala. Tesis Aislada. Civil CXLII/2007. Registro: 172050. Semanario Judicial de la Federación y su Gaceta, Tomo xxvi, Pág. 260. (Julio de 2007): “Derecho A LA IDENTIDAD DE LOS MENORES. CONTENIDO.- El artículo 7 de la Convención sobre los Derechos del Niño (ratificada por el Estado Mexicano y publicada en el Diario Oficial de la Federación el 25 de enero de 1991) dispone que el niño tiene derecho desde que nace a un nombre, a adquirir una nacionalidad y en la medida de lo posible a conocer a sus padres y a ser cuidado por ellos. En concordancia con lo anterior y conforme al numeral 3 de la Ley para la Protección de los Derechos de Niñas, Niños y Adolescentes (de orden público, interés social y observancia obligatoria para toda la República), son principios rectores de la protección de los menores, entre otros, el del interés superior de la infancia y el de la tutela plena e igualitaria de los derechos humanos y de las garantías constitucionales. En ese
}

Cabe señalar que, de acuerdo con el artículo 8 de la Convención sobre los Derechos del Niño, se establece que los Estados partes deben comprometerse a respetar los derechos del niño y a preservar su identidad, nacionalidad y nombre, así como las relaciones familiares de conformidad con la ley, sin injerencias ilícitas. Asimismo, cuando un niño sea privado ilegalmente de algunos de los elementos de su identidad o de todos ellos, los Estados partes deberán prestar la asistencia y protección apropiadas con miras a restablecer rápidamente su identidad. ${ }^{16}$ Se observa que este precepto se distingue de los otros, al establecer que los demás Estados parte de dicha convención tienen la obligación de intervenir y prestar su asistencia, con el fin de salvaguardar los derechos de identidad del menor. Cabe mencionar, a guisa de ejemplo, cómo algunos de los Estados partes son potencias mundiales - tales como Alemania y China-, de manera que es este un tema controversial, ya que podría estarse violentando el "principio de no intervención" que en México tiene rango constitucional, conforme al artículo $89 .{ }^{17}$ Con respecto a tal situación, Vargas Carreño señala:

La preocupación, en un mundo interdependiente y globalizado, de algunos Estados por la situación de los derechos humanos en otros y el creciente interés de la propia comunidad internacional por asegurar la vigencia de esos derechos, ha hecho surgir en algunos casos una aparente o real antinomia entre la vigencia del principio de no intervención y la preocupación de los Estados e instituciones internacionales por asegurar una efectiva protección de los derechos humanos, cualquiera que sea el Estado en que éstos sean violados. ${ }^{18}$

tenor, el artículo 22 de dicha Ley establece el derecho a la identidad, el cual se compone por el derecho a tener un nombre y los apellidos de los padres desde que nazca, a tener una nacionalidad y a conocer su filiación y su origen, salvo en el caso que las leyes lo prohíban. Así, el hecho de que el menor tenga la certeza de quién es su progenitor, constituye un principio de orden público que es parte del núcleo esencial del derecho fundamental a la personalidad jurídica, cuya importancia no sólo radica en la posibilidad de solicitar y recibir información sobre su origen, la identidad de sus padres y el conocimiento de su origen genético, sino que a partir de esos elementos puede derivarse, por una parte, su derecho a tener una nacionalidad $y$, por otra, el derecho a que sus ascendientes satisfagan sus necesidades de alimentación, salud, educación y sano esparcimiento, para su desarrollo pleno e integral."

16. Véase Convención Sobre los Derechos del Niño 1990. 17. Cf. Constitución Política de los Estados Unidos Mexicanos. Artículo 89. (México).

18. Véase Edmundo Vargas Carreño. EL PRINCIPIO DE NO INTERVENCIÓN Y SU VIGENCIA EN EL DERECHO INTERNACIONAL DEL SigLo XXI. Instituto de Investigaciones Jurídicas, UNAM. Disponible en http://www.juridicas.unam.mx/inst/evacad/eventos/2004/0902/ mesa3/62s.pdf 


\section{LA REFORMA AL ARTÍCULO 4 DE la Constitución Política de los Estados Unidos Mexicanos}

$\mathrm{Al}$ entrar en vigor, entre otras, la reforma al artículo 4 de la Constitución Política de los Estados Unidos Mexicanos, el 18 de junio del 2014, consistente en la adición de un párrafo octavo a su texto, se desprende de los transitorios del decreto lo siguiente:

SEGUNDO. A partir de la entrada en vigor del presente Decreto, las Legislaturas de los Estados y la Asamblea Legislativa del Distrito Federal, dispondrán de seis meses para establecer en sus haciendas o códigos financieros la exención de cobro del derecho por el registro de nacimiento y la expedición de la primera copia certificada del acta de nacimiento.

TERCERo. El Congreso de la Unión en un plazo no mayor a seis meses a partir de la entrada en vigor del presente Decreto, y previa opinión de las entidades federativas y la autoridad competente en materia de registro nacional de población, deberá realizar las adecuaciones a la ley que determinen las características, diseño y contenido del formato único en materia de registro de población, así como para la expedición de toda acta del registro civil que deberá implementarse a través de mecanismos electrónicos y adoptarse por las propias entidades federativas del país y por las representaciones de México en el exterior. ${ }^{19}$

Cabe notar que tal adición al artículo 4 de la Constitución Política de los Estados Unidos Mexicanos, no es resolutiva del problema que ocupa al presente trabajo, ni mucho menos lo establecido en los transitorios del decreto correspondiente que han quedado transcritos. Sin embargo, es importante puntualizar que la Comisión Permanente del H. Congreso de la Unión haya incorporado en la parte dogmática de los derechos humanos, precisados en el Documento Fundamental del país, tales potestades, lo cual dará pie a modificar parte de la infraestructura utilizada en las oficialías del Registro Civil ${ }^{20}$ de todas las entidades

19. Véase Decreto por el que se adiciona el Artículo $4^{\circ}$ de la Constitución Política de los Estados Unidos Mexicanos, vigente a partir del 18 de junio de 2014. Junio 17 de 2014. Diario Oficial de la Federación.

20. Véase Hegel Cortés Miranda. El Registro Civil a 150 años. BiblioTECA JuRídica Virtual del Instituto de InVestigaciones Jurídicas de la unam. Pág. 36. Disponible en http://archivos.juridicas.unam.mx/ www/bjv/libros/7/3067/4.pdf

En primer término, se puede mencionar el aspecto legislativo, en el que generalmente la realidad ha rebasado la norma, y hoy en día federativas de la República Mexicana y del Distrito Federal, para el aseguramiento de esos derechos.

Por otra parte, por lo que respecta al aspecto fiscal, también cobra relevancia señalar un aspecto conceptual, ya que la palabra derecho en los Estados Unidos Mexicanos también tiene por acepción la de ser una clase de "contribución", y es inadecuado que en el segundo transitorio de dicho decreto se utilice la expresión exención de cobro del derecho, ya que la exención solo puede ser de pago, no de cobro, y es favorable al sujeto pasivo obligado, por lo que se puede prestar a confusión la expresión ahí utilizada, dado que eso presumiría que los registros de nacimiento seguirían siendo considerados hechos generadores de obligaciones tributarias. No obstante, en este caso en particular, los solicitantes del servicio estarían relevados de darle cumplimiento. Independientemente de la falta de técnica jurídico-legislativa, este último aspecto libera, en una mínima parte, uno de los inconvenientes que tienen algunas personas para registrar el nacimiento de otras.

\section{Sobre EL REgISTRO DE NACIMIENTO}

El Fondo de las Naciones Unidas para la Infancia (UNICEF), junto con el Instituto Nacional de Estadística y Geografía (INEGI), han abordado la problemática y emitieron en conjunto el documento Derecho a la Identidad. La cobertura del registro de nacimiento en México en 1999 y 2009, por el cual se reconoce que:

El registro de nacimiento es la constancia permanente y oficial del nacimiento de un niño o niña que un determinado nivel administrativo del Estado se asienta en un archivo, bajo la coordinación de un particular ramo de gobierno (...) En el caso de México, el registro de nacimiento y la emisión de las actas respectivas mediante las cuales se hacen constar, corresponde a las oficinas del registro civil. ${ }^{21}$

muchos de los procesos tecnológicos y administrativos que permiten ofrecer mejores servicios se encuentran completamente al margen de la ley y no cuentan con una regulación propicia, por lo que es necesario que para dotar de mayor certeza jurídica a estos procedimientos se contemplen dentro del texto, dando el evidente margen de flexibilidad que permita su interpretación y adaptación a través del tiempo.

21. Véase unicef. Derecho a la Identidad. La cobertura del REGISTRO DE NACIMIENTO EN MÉxiCO EN 1999 Y 2009. Disponible en http://www.unicef.org/mexico/spanish/mx_registrodenacimiento(1). pdf 
De esta cita se desprende que la autoridad encargada de gestionar el registro de los seres humanos para que ellos tengan identidad es el Registro Civil, el cual es un órgano administrativo dependiente del Poder Ejecutivo del Estado, el cual fue monopolizado por el mismo debido a la trascendencia de su actuación y separado de la Iglesia católica desde la época del presidente Benito Juárez y la promulgación de las Leyes de Reforma, siendo de especial trascendencia la Ley Orgánica del Registro Civil o Ley sobre el Estado Civil de las Personas de 1859, en la cual se estableció por primera vez que en toda la República Mexicana existieran funcionarios públicos que tendrán a su cargo la averiguación y modo de hacer constar el estado civil de todos los mexicanos y extranjeros residentes en el territorio nacional, por cuanto concerniera a su nacimiento, adopción, reconocimiento, matrimonio y fallecimiento.

El INEGI reconoce que los niños y niñas cuyos nacimientos no han sido registrados son estadísticamente invisibles en muchas esferas sociales, lo que los afecta en múltiples aspectos de sus vidas, mermando las oportunidades de desarrollo. Por lo tanto, los niños se ven afectados al no poder acceder a los servicios públicos proporcionados por el Estado, incluyendo el de salud, ya que se dejan desprotegidos y esto puede llegar a causar, incluso, su muerte por falta de atención.

El Centro de Investigaciones Innocenti, a través de UNICEF, analiza la problemática al estudiar las consecuencias de la inadecuada gestión del registro civil. En este sentido, el centro señala:

Idealmente, la inscripción de los nacimientos forma parte de un sistema eficaz de registro civil que reconoce la existencia de la persona ante la ley, establece los vínculos familiares del niño y recorre la trayectoria de los acontecimientos fundamentales en el vivir de un individuo, desde el nacimiento con vida, hasta el matrimonio y la muerte..$^{22}$

Posteriormente, en la misma publicación se hace referencia a que el certificado de nacimiento es la prueba más visible del reconocimiento legal por parte de un gobierno.

La falta de registro de los niños nacidos, se presenta en nuestro país y en otros de América Latina que comparten un nivel de desarrollo económico semejante. Así es, por ejemplo, el caso de Paraguay,

22. Véase unicef. El Registro de Nacimiento, El Derecho a tener Derechos. Fondo de las Naciones Unidas de la Infancia, Centro de Investigaciones Innocenti. (2002). Pág. 2. Disponible en https://www.unicef-irc.org/publications/pdf/digest9s.pdf en donde se publicó en el 2004 el artículo "La niñez y el derecho al reconocimiento de la personalidad jurídica". En este se expone lo siguiente:

El registro del estado civil de niños y niñas, pese a ser un elemento central de la personalidad jurídica que define circunstancias fundamentales de la sociedad y el Estado - tales como el nombre, la edad y ubicación jurídica en el núcleo familiar y social-, enfrenta en Paraguay un sistema ineficiente de inscripción para los nacidos vivos, con un alto saldo de niños y niñas que nacen y mueren sin haber sido registrados, en violación a sus derechos fundamentales. ${ }^{23}$

Tal situación puede llegar a considerarse una forma de atentar contra el menor. En este sentido, el artículo escrito por Portillo-González, "Omisión del registro del nombre de un niño: otra forma de maltrato infantil", expone: "La omisión de la inscripción del nombre por los padres o custodios niega a los infantes el reconocimiento como persona y, por lo tanto, al goce de derechos como la educación, salud, etc. Ya que los gobiernos no pueden presupuestar sobre la base de registros incompletos". ${ }^{24}$ Este autor también identifica la trascendencia del registro de menores en relación con la operatividad del Estado. La falta de registro, como ya se ha señalado, tiene un doble impacto con respecto a los derechos de los menores, sus progenitores y con respecto a la actuación administrativa. En este último aspecto, se debe advertir que la capacidad de reacción del gobierno depende, en primer lugar, de saber a quiénes y a cuántos se destinan las políticas y acciones públicas.

Recapitulando, el registro de nacimiento se traduce, principalmente, en la asignación del nombre que un ser humano llevará el resto de su vida. Como ya se ha mencionado, es uno de los atributos de la persona física, además del domicilio, la nacionalidad, el estado civil, la capacidad y el patrimonio. El nombre es considerado como un derecho personalísimo que le corresponde a cada persona, y como tal, es inalienable, imprescriptible e irrenunciable.

De este modo, el nombre permite, junto con otros elementos, acreditar la identidad de una persona y distinguirla entre otras, por lo que es importante

\footnotetext{
23. Véase Andrea Cristina Vera-Aldana. La niÑez y el Derecho AL RECONOCIMIENTO DE LA PERSONALIDAD JURÍDICA, DERECHOS Humanos. (2004). Disponible en http://bibliotecavirtual.clacso. org.ar/Paraguay/ cde/20121018 040104/ninez.pdf 24. Véase Armando F. Portillo-González. Omisión del registro del nombre de un niño: otra forma de maltrato infantil. ACTA PEDIÁtRICA DE México 29(5). 2008. Págs. 285-90.
} 
entonces señalar cómo se conforma este, conforme al artículo 36 del Código Civil del Estado de Querétaro:

El nombre propio podrá constar de uno o varios vocativos, con los que se designe individualmente a una persona. Desde luego, en el caso de las personas físicas, se indicará por quienes los presenten ante el Oficial del Registro Civil (...) La conformación del nombre responde, según cada país, región o comunidad a diversas tradiciones, sin embargo, el derecho ha debido encontrar la fórmula más laxa para que éste se integre con el fin de identificar a la persona. La capacidad de identificación evita una posible confusión en la atribución de derechos u obligaciones a una persona, en cualquier caso, el objeto de estudio del artículo se reconduce a la falta de identidad. ${ }^{25}$

Este punto interesa por cuanto tal situación no permite al Estado tratar con cierta "especialidad" a quienes no tienen un nombre. En este sentido, debemos recordar que el principio pro homine ${ }^{26}$ exigiría a las autoridades resolver o atender con relación a lo más favorable a las personas que, sin nombre, no es posible distinguirlas unas de otras, o unas circunstancias de otras.

\section{DimenSIONES DEL PROBLEMA Y SUS PUNTOS DE INFLEXIÓN}

Las consecuencias del problema de investigación se presentan en tres dimensiones.

En la fáctica, la negativa de servicios que proporciona el Estado, como lo son: acceso a la salud, a que se le administre justicia por parte de los tribunales, a la

25. Véase Karla Cantoral Domínguez. El Derecho a la identidad de un menor: el caso de México. Revista boliviana DE DeRECHo 20. Julio 2015. Pág. 74. En el caso de menores, la falta de registro de nacimiento los coloca en una situación de gran vulnerabilidad, porque les impide ejercer otras prerrogativas, tales como el acceso a la educación, servicios de salud, la expedición de un pasaporte, inclusive el derecho a que el menor pueda conocer exactamente la fecha de nacimiento y sus orígenes.

26. Ximena Urquiaga Medellín. Principio pro persona, metoDOLOGÍA PARA LA ENSEÑANZA DE LA REFORMA CONSTITUCIONAL. Pág. 20. Disponible en http://www2.scjn.gob.mx/red/coordinacion/ archivos_Principio\%20pro\%20persona.pdf: "La complejidad intrínseca del principio pro persona implica que no existe una sola fuente normativa o jurisprudencial que pueda proporcionar una visión integral de su contenido. Por el contrario, para poder entenderlo más profundamente, con el objetivo de determinar cómo podría operar en casos concretos, es necesario referirse a criterios de interpretación establecidos por distintos tribunales". participación en programas de desarrollo y seguridad social, adopción, posesión de tierras, posibilidad de celebrar matrimonio, educación, entre otras, además de que se les dificulta la integración a la vida económica y política del país, ante la imposibilidad de trabajar formalmente o votar.

En la axiológica, se corre el riesgo de excluir al ser humano de la sociedad, al carecer de una identidad oficial, de un nombre reconocido, de una nacionalidad y negársele la protección de los valores con los que todo ser humano debe contar.

Por lo tanto, es importante recalcar que el ser humano que no es registrado pierde la oportunidad de tener seguridad jurídica:

La seguridad jurídica debe ser analizada desde dos puntos de vista o aspectos, uno de ellos el subjetivo, el cual consiste en la convicción que tiene el ciudadano de que sus derechos, posesiones y propiedades le serán respetadas, para la cual debe existir una organización del Estado, a través de leyes, órganos jurisdiccionales y policiacas. El otro aspecto es el objetivo, el cual consiste en que esa organización del Estado, sea un orden justo y efectivo, que haga cumplir sus determinaciones, cuando éstas no sean acatadas voluntariamente, incluso por la fuerza pública. ${ }^{27}$

De esta cita cabe destacarse cómo para que exista seguridad jurídica en ambos puntos de vista, es necesario que el ser humano sea reconocido por el Estado, a fin de que este proteja su ser y sus bienes, garantizándolo por medio de la ley, e incluso por la fuerza pública en caso de que sus derechos sean vulnerados, situación de la que se ve privado el ser humano no registrado.

Además, el ser humano que no es registrado carece de trato como igual entre los demás que conforman su sociedad, de manera que puede caer en la discriminación en el aspecto incluso económico, debido a que dichos seres humanos carecen de igual acceso a la distribución de bienes considerada por Dworkin:

No deben distribuirse bienes u oportunidades de manera desigual sobre la base de que algunos ciudadanos tienen derecho a más porque merecen mayor consideración. El Estado no debe restringir la libertad sobre la base de que la concepción de la vida buena de un ciudadano es más noble o superior que la de otros. ${ }^{28}$

27. Véase Jesús Sotomayor Garza. Deontología del abogado. Editorial Porrúa. (2013). Pág. 29.

28. Véase Ronald Dworkin. Los DeRECHOS EN SERIO. Ariel. (1984). Pág. 273. 
En la normativa, el derecho a la identidad previsto en el artículo 4 de la Constitución, en los términos ya señalados, constituye el fundamento legal que debe sostener el análisis de la realidad en torno a la protección de los seres humanos que carecen de un nombre. Además, el artículo 1 del mismo texto legal, también participa en la construcción de un andamiaje jurídico al establecer en su primer y tercer párrafo:

En los Estados Unidos Mexicanos todas las personas gozarán de los derechos humanos reconocidos en esta Constitución y en los tratados internacionales de los que el Estado Mexicano sea parte, así como de las garantías para su protección (...) Todas las autoridades, en el ámbito de sus competencias, tienen la obligación de promover, respetar, proteger y garantizar los derechos humanos de conformidad con los principios de universalidad, interdependencia, indivisibilidad y progresividad. En consecuencia, el Estado deberá prevenir, investigar, sancionar y reparar las violaciones a los derechos humanos, en los términos que establezca la ley. ${ }^{29}$

En este sentido, el párrafo primero explicita el término personas, de uso en el lenjuage jurídico asociado al nombre. El tercero, implica el supuesto señalado en torno a la protección del nombre con respecto a la actuación de las administraciones públicas que deben favorecer el registro.

Así, las autoridades administrativas en su ámbito de competencia respecto al registro de nacimientos, deben en todo momento proteger, promover, respetar y garantizar el derecho a la identidad, de acuerdo con los principios de universalidad, interdependencia, indivisibilidad y progresividad de los derechos humanos. ${ }^{30}$

\footnotetext{
29. Véase Constitución Política de los Estados Unidos Mexicanos, supra, nota 19

30. Véase Tribunales Colegiados de Circuito. Tesis Aislada I.4 .A.9.K (10 ${ }^{\mathrm{a}}$.). Semanario Judicial de la Federación y su Gaceta, Registro 2003350, Décima Época, Libro xIx, Tomo 3. (Abril de 2013). Pág. 2254. “-PRINCIPIOS DE UNIVERSALIDAD, INTERPDEPENDENCIA, INDIVISIBILIDAD, PROGRESIVA DE LOS DERECHOS HUMANOS. EN QUÉ CONSISTEN.- El tercer párrafo del artículo 1o. de la Constitución Política de los Estados Unidos Mexicanos dispone, entre otras cuestiones, que todas las autoridades, en el ámbito de sus competencias, tienen la obligación de promover, respetar, proteger y garantizar los derechos humanos de conformidad con los principios de universalidad, interdependencia, indivisibilidad y progresividad, los que consisten en lo siguiente: i) universalidad: que son inherentes a todos y conciernen a la comunidad internacional en su totalidad; en esta medida, son inviolables, lo que no quiere decir que sean absolutos, sino que son protegidos porque no puede infringirse la dignidad humana (...) ii) interdependencia e indivisibilidad: que están relacionados entre sí, esto es, no puede
}

También es necesario mencionar que en los Estados Unidos Mexicanos, el juicio de amparo se ha erigido como el medio de control constitucional cuyo objeto, entre otros, es resolver las controversias que se susciten por normas generales, actos $\mathrm{u}$ omisiones que violen los derechos humanos reconocidos y las garantías otorgadas para su protección por la Constitución Política de los Estados Unidos Mexicanos y los tratados internacionales de los que el Estado mexicano sea parte. El juicio de amparo es el medio para la protección de los derechos humanos por excelencia, y este medio quedaría vedado para quien no tenga un nombre. En el entendido que la falta de identidad es el principio de la vulneración de una serie de derechos, se debe observar y poner énfasis en que la estructura jurídica para la protección de los derechos humanos formalmente condiciona la protección de quien lo padece. De aquí la importancia de la concepción de los principios de progresividad, interdependencia, indivisibilidad y universalidad anteriormente mencionados frente al texto de la ley. En este sentido, la Ley de Amparo señala que este proceso se seguirá siempre a instancia de parte agraviada, llamada "quejoso", teniendo tal carácter quien aduce ser titular de un derecho subjetivo o de un interés legítimo individual o colectivo, ${ }^{31}$ y sufre una violación en los términos señalados en el párrafo anterior, y con ello se le produce una afectación real y actual en su esfera jurídica, ya sea de manera directa o en virtud de su especial actuación

hacerse ninguna separación ni pensar que unos son más importan tes que otros, deben interpretarse y tomarse en su conjunto y no como elementos aislados. Todos los derechos humanos y las libertades fundamentales son indivisibles e interdependientes; debe darse igual atención y urgente consideración a la aplicación, promoción y protección de los derechos civiles, políticos, económicos, sociales y culturales; esto es, complementarse, potenciarse o reforzarse recíprocamente; y iii) progresividad: constituye el compromiso de los Estados para adoptar providencias, tanto a nivel interno como mediante la cooperación internacional, especialmente económica y técnica, para lograr progresivamente la plena efectividad de los derechos que se derivan de las normas económicas, sociales y sobre educación, ciencia y cultura, principio que no puede entenderse en el sentido de que los gobiernos no tengan la obligación inmediata de empeñarse por lograr la realización íntegra de tales derechos, sino en la posibilidad de ir avanzando gradual y constantemente hacia su más completa realización, en función de sus recursos materiales; así, este principio exige que a medida que mejora el nivel de desarrollo de un Estado, mejore el nivel de compromiso de garantizar los derechos económicos, sociales y culturales".

31. Véase Eduardo Gabino Castrejón García. El interés legítimo y jurídico en el sistema de impartición de justicia. AíDA. ÓPERA PrIMA De Derecho Administrativo 11. Pág. 53. Disponible en http:// historico.juridicas.unam.mx/publica/librev/rev/aida/cont/11/art/ art2.pdf: "El interés legítimo se encuentra relacionado con la presunción de afectación a la esfera jurídica de una persona, por la simple emisión de un acto de autoridad". 
frente al orden jurídico, según lo establece la fracción I, del artículo 5 de la Ley de Amparo, Reglamentaria de los artículos 103 y 107 de la Constitución Política de los Estados Unidos Mexicanos.

Según lo anterior, si el carácter de quejoso lo tiene quien aduce ser titular de un derecho subjetivo o de un interés legítimo individual o colectivo, ese quien debe ser un quien jurídico, es decir, una persona, porque de otro modo, al no tratarse de un quien jurídico persona, no se estaría refiriendo a un actor de la escena jurídica y, por ende, no sería comprensible que se afectara la esfera jurídica de alguien que no es persona.

En un orden jurídico que se precie de ser garantista, como el de México, se consagran en su Constitución Política disposiciones relativas a los derechos inherentes a cualquier individuo, a los cuales Ferrajoli denomina "derechos fundamentales", y los define como:

Todos aquellos derechos subjetivos que corresponden universalmente a $<<$ todos $>>$ los seres humanos en cuanto dotados del status de personas, de ciudadanos o personas con capacidad de obrar; entendiendo por $<<$ derecho subjetivo $>>$ cualquier expectativa (de prestaciones) o negativa (de no sufrir lesiones) adscrita a un sujeto por una norma jurídica; y por $<<$ status $>>$ la condición de un sujeto, prevista asimismo por una norma jurídica positiva, como presupuesto de su idoneidad para ser titular de situaciones jurídicas y/o autor de los actos que son ejercicio de éstas. ${ }^{32}$

De lo anterior se colige que el derecho a la identidad es un derecho humano y fundamental previsto en el artículo 4 constitucional, y como tal, debería ser garantizado por el Estado brindando los medios que faciliten su ejercicio; de otra manera, cualquier disposición que lo entorpezca y burocratice, sería inconstitucional y violatorio de dicho derecho humano. Sin embargo, puede observarse que en las normas que regulan el acceso al nombre en el estado de Querétaro, ha quedado preceptuada una serie de requisitos que difícilmente se cumplen en una gran cantidad de ocasiones, debido a las circunstancias en que se encuentran los progenitores. Sirva para exhibir lo anterior algunas de las fracciones del artículo 74 del Código Civil del Estado de Querétaro que prevén requisitos que deben cumplir los padres para el registro: "III. Que se le exhiba, en su caso, el acta de matrimonio de los padres para que se asiente el nombre de éstos como los progenitores (...) IV. Identificar a quienes presentan al menor y a los testigos (...) v. Requerir,

32. Véase Luigi Ferrajoli. Los fundAmentos DE LOS DEREChos Fundamentales. Editorial Trotta. (2001). Pág. 1. preferentemente, copia del acta de nacimiento de los padres". ${ }^{33}$

Cabe mencionar que los padres tienen la obligación de declarar el nacimiento, dentro de los ciento ochenta días siguientes a la fecha en que hubiere ocurrido, acudiendo a las oficinas de manera conjunta o separada, o a falta de ellos, los abuelos paternos o maternos o quienes tengan a su cargo el cuidado o custodia del menor.

Incluso, se establecen mayores requisitos al tratarse de registros de menores de hasta cuatro años de edad, solicitando el oficial del Registro Civil la constancia de no haber sido registrado con anterioridad; asimismo, que quien lo presente, tenga residencia en el lugar en donde actúa el oficial del Registro Civil que corresponda.

Sin embargo, la falta de registro de nacimientos se encuentra, principalmente, en las comunidades alejadas de la zona conurbada y en las zonas donde los seres humanos viven en pobreza en las calles, ${ }^{34} \mathrm{y}$ quienes a su vez son hijos de padres no registrados y son progenitores de menores en las mismas circunstancias, los cuales carecen de conocimiento jurídico; muchos de ellos, por temor, no se acercan a las oficinas gubernamentales a pedir asesoría.

$\mathrm{Al}$ ser esto un hecho evidente, dichos seres humanos no cuentan con identificación para presentar a su menor en el Registro Civil, tampoco cuentan con su propia acta de nacimiento, ni con acta de matrimonio, ni con constancia de alumbramiento, ya que las mujeres no reciben atención médica y no pueden acreditar su residencia.

Además, puede observarse que en el artículo 132 del susodicho Código Civil del Estado de Querétaro, se establecen los requisitos que permiten llevar a cabo el trámite para el registro extemporáneo de seres humanos mayores de cuatro años, el mismo que debe realizarse ante la Dirección Estatal del Registro Civil, con una solicitud por escrito, la cual, de manera personal, debe presentarse por el interesado o sus representantes legales, acompañado de la constancia expedida por autoridad municipal que acredite la residencia del interesado, la constancia expedida por la autoridad del Registro Civil del lugar de nacimiento, la constancia de nacimiento del interesado, dos testigos mayores de edad a quienes les consten los hechos y los documentos

\footnotetext{
33. Véase Código Civil del Estado de Querétaro. (México). 34. Cf. Secretaría de Desarrollo Social, Subsecretaría de Planeación, Evaluación y Desarrollo Regional. INFORME ANUAL SOBRE LA SitUACIÓN DE POBREZA Y REZAgo SOCIAL 2016. Disponible en http://www.gob.mx/cms/uploads/attachment/file/50347/Quer_ taro.pdf Este informe refleja que en el estado de Querétaro, se registra un porcentaje de $34,2 \%$ de población en situación de pobreza.
} 
públicos o privados mediante los cuales se acredite el uso del nombre que se pondrá al registrado; es posible que, en caso de tratarse de menores de edad, los tres últimos mencionados sean sustituidos por un dictamen emitido por la Procuraduría de la Defensa del Menor y la Familia del Estado. ${ }^{35}$

En la misma disposición, se expresa que en caso de radicar en un municipio distinto de la sede de la Dirección Estatal del Registro Civil, dicha solicitud de inscripción debe presentarse ante el oficial del Registro Civil correspondiente a su domicilio, quien deberá remitirla en un plazo no mayor a diez días para que la Dirección Estatal del Registro Civil resuelva, a más tardar en treinta días hábiles, y en caso de resultar favorable se realice la inscripción respectiva, notificando a la Oficialía del Registro Civil del municipio correspondiente y se envíe un ejemplar para que integre su archivo documental y, en caso de ser una resolución negativa, el interesado puede hacer valer su pretensión ante un juez competente.

Desde el supuesto mencionado previamente con respecto a los seres humanos que se encuentran en comunidades alejadas de las zonas conurbadas o que viven en las calles, se puede observar que dichos requisitos son igualmente difíciles de cumplir, dadas sus condiciones económicas, sociales y educativas.

Por otro lado, resulta importante señalar circunstancias especiales que han sido reconocidas por el legislador. Al respecto, el artículo 79 señala que los recién nacidos que sean encontrados en situación de desamparo, serán dotados de un acta de nacimiento, en la que se denunciará ante el Ministerio Público, ${ }^{36}$ en dónde y cuándo se encontraron, así como la presentación de vestigios que pudieran conducir a su posterior

35. La Procuraduría de la Defensa del Menor y la Familia del Estado de Querétaro, entre otras actividades, expide dictámenes de nacimiento y coadyuva en el registro de los menores abandonados o expósitos, así como en el registro extemporáneo de menores. $C f$. http://sitios. dif.gob.mx/pdmf/directorio-de-procuradurias/queretaro/

36. En el Periódico Oficial del Gobierno del estado de Querétaro, LA SOMBRa De ARTEAgA, Tomo cXlix, N.o. 27, publicado el 13 de mayo del 2016, se publicó la ley que reforma y adiciona disposiciones de la Constitución Política del Estado de Querétaro, en la cual, se adiciona, entre otros, al artículo 30 Bis, lo siguiente: "El Ministerio Público es la institución que tiene por objeto investigar y perseguir los delitos; promover la solución de controversias a través de mecanismos alternativos, sin perjuicio de la competencia que en este ámbito corresponda a otras autoridades. El Ministerio Público se organizará en una Fiscalía General del Estado, como organismo constitucional autónomo dotado de personalidad jurídica y patrimonio propios que se regirá por su Ley. Dicho organismo constitucional autónomo contará con un Consejo, en el que se garantice la participación ciudadana; con un cuerpo de policía de investigación que actuará bajo la conducción y mando del Ministerio Público, con una Unidad Especializada en Delitos Electorales y las demás que establezca su Ley". reconocimiento, con el fin de que entonces se inicie la averiguación al respecto. Asimismo, se da aviso a la Procuraduría de la Defensa del Menor y a la Familia del Estado, y se señala, por parte de un perito, cuál es el estado físico en que el menor se encuentra y su edad aparente, para entonces designar una persona o institución que se encargará del menor y de su inscripción en el Registro Civil, asignándole un nombre de uso común en la región, siendo anulable el acta de registro solo si se conoce la filiación del menor y que esta sea declarada por la autoridad judicial competente.

Como es de apreciarse, de los preceptos anteriores se desprende la mención de múltiples requisitos que resultan lentos y complicados para obtener el registro de nacimiento, los cuales en ocasiones no pueden cubrirse.

El Estado, al conocer la problemática y velando por el interés público, debería facilitar el proceso de registro para que todos los seres humanos que viven dentro del territorio, reconozcan la factibilidad de ser registrados y puedan ejercitar sus derechos. Dicha situación, no solo ayudaría a que todos los seres humanos tengan personalidad jurídica, sino que también beneficiaría al propio aparato gubernamental, ya que conocería, de manera precisa, cuántos y quiénes son los ciudadanos con los que cuenta el país y así, estar en posibilidades de crear políticas públicas en materia de seguridad, educación, desarrollo social y económico que impulsen a la nación.

Si bien es cierto en el artículo 4 constitucional, octavo párrafo, se establece que la autoridad competente expedirá gratuitamente la primera copia certificada del acta de registro de nacimiento, tal medida no ha sido suficiente para erradicar el problema, ya que el proceso de registro sigue siendo complicado para los grupos vulnerables.

Como mencioné con anterioridad, la norma ha sido sobrepasada por los hechos, de modo que existe discrepancia entre la realidad y la normatividad vigente, y las disposiciones regulatorias del trámite de registro de nacimiento representan, en gran medida, el origen del problema que ocupa a este artículo.

En el ámbito federal, la Ley para la Protección de los Derechos de Niños, Niñas y Adolescentes del año 2000, establece en su artículo $22,{ }^{37}$ además del derecho a la identidad que se compone de nombre y apellidos de los padres desde el nacimiento, a ser inscrito en el Registro Civil, tener una nacionalidad - de acuerdo con lo establecido en la Constitución-, a conocer su filiación y su origen - salvo en los casos que las leyes

37. Cf. Ley para la Protección de los Derechos de Niños, Niñas y Adolescentes del año 2000. 
lo prohíban-, y a pertenecer a un grupo cultural. Se establece también que las normas de cada entidad federativa podrán disponer lo necesario para que la madre y el padre los registren sin distinción, en virtud de las circunstancias de su nacimiento. Sin embargo, como se aprecia, en la realidad no resulta nada fácil ejercerlo.

En el Reporte sobre la Discriminación en México 2012, se puntualiza que:

En lo que toca al derecho al nombre destaca el rígido formalismo persistente en las oficinas del Registro Civil que, entre otras consecuencias, hace que las personas difícilmente puedan portar nombres de procedencia indígena, padezcan complicaciones para corregir su acta de nacimiento o para modificar el nombre - salvaguardando los derechos relativos a la intimidad y la privacidad - por razones de cambio en la identidad sexo genérica. Aquí también se hace referencia a los costes que, para ciertos segmentos de la población, se hacen prohibitivos cuando las oficinas del Registro Civil se hallan lejos del lugar de residencia, o cuando las copias del acta de nacimiento implican una erogación injusta. De acuerdo con la investigación realizada, aún subsiste en el país un grupo de aproximadamente 7 millones de mexicanas y mexicanos que no cuentan con acta de nacimiento, lo cual redunda en la imposibilidad material de acceder a muchos de los derechos que la Constitución y las leyes prevén. Particular vulnerabilidad a este respecto padecen las personas adultas mayores, así como las y los niños de las zonas rurales y las comunidades indígenas. ${ }^{38}$

Estos datos hablan de la gravedad del problema, considerada la exponencial proyección de vulneración de derechos que representa no tener un nombre; se trata, en todo caso, de un grave escollo jurídico para la protección del ser humano.

\footnotetext{
38. Véase Acacio Alcides Morales. El cambio de nombre. Revista Jurídica Mario Alario D’Filippo. Pág. 131. Disponible en file:///C:/ Users/aux2/Downloads/Dialnet-ElCambioDeNombre-4767712\%20 (1).pdf Dada la característica de ser el nombre una función identificadora, él, y principalmente el apellido, ofrecen aspectos del derecho público aunque son derecho subjetivo privado, pues es en este interés público de individualización y diferenciación de sus miembros en el que el ordenamiento jurídico hace obligatorio el uso del nombre civil a favor de la identidad como derecho de toda persona a conocer su origen biológico, o el carácter de su vínculo familiar, que está ligado indisolublemente a la dignidad del hombre por cuanto la identidad personal tiene su fundamento axiológico en la dignidad humana.
}

\section{Supuestos FÁCticos CONTRA LA DIGNIDAD DEL SER HUMANO}

Hablar de la dignidad del ser humano es hablar de un valor fundamental del mismo, que abarcaría, entre otros aspectos, la libertad de ser y hacer lo deseado por aquél, según lo preceptuado por la Constitución Política de los Estados Unidos Mexicanos y demás ordenamientos secundarios, así como por los tratados internacionales.

La Carta Magna consagra en sus artículos 1, párrafo cinco; 2 , apartado A, fracción II; 3, fracción II, inciso c); 4, párrafo octavo; 25, primer párrafo; y, 123 , primer párrafo, la referencia a dicha dignidad, con respecto a: la no discriminación; la libertad para que los pueblos y comunidades indígenas se determinen, particularizando sobre las mujeres; el fortalecimiento del aprecio y respeto por ella; el derecho a disfrutar de una vivienda; la rectoría del Estado sobre el desarrollo nacional con el afán de que sea integral y sustentable, con el propósito de permitir el pleno ejercicio de dicha dignidad; y el derecho al trabajo.

Corresponde ahora precisar algunas de las implicaciones que tendría la falta de registro del nacimiento de un ser humano ante una oficialía del Registro Civil mexicana, todas traducidas en un atentando contra su dignidad. Para esto, se menciona la descripción concatenada de diversos escenarios concretos y cotidianos que a manera de ejemplo se redactan, en los que se le denominará "ser humano", por no tener un nombre reconocido oficialmente al no haberse registrado nunca su nacimiento, y por ser una categoría igualmente aplicable para mujeres y hombres.

Un primer caso puede implicar a un ser humano nacido en el territorio de los Estados Unidos Mexicanos, pero sus padres no acuden a registrarlo ante una oficialía del Registro Civil, aunado a que el nacimiento de los padres tampoco ha sido registrado en los términos de las disposiciones legales correspondientes. Dicho ser humano enferma de gravedad y, por tanto, requiere atención médica y acuden al centro de salud más cercano. Sin embargo, a los padres se les indica que deben presentar un documento de identificación oficial y señalar el nombre de su hijo, lo cual les resulta imposible, toda vez que su nacimiento no ha sido registrado ni cuentan con la documentación necesaria para que se le expida una identificación oficial. El encargado del centro de salud les señala que no se le puede brindar atención médica, lo cual puede ocasionar secuelas de importancia en su integridad física o incluso la muerte. 
Un segundo supuesto corresponde a un ser humano que es de oficio carpintero y le ha sido solicitado un trabajo de reparación. Una vez ha prestado el servicio, pide a quien se lo solicitó le pague la contraprestación correspondiente, y este se niega a hacerlo. En consecuencia, dicho ser humano procede a redactar un escrito dirigido a un juez, mediante el cual demanda se le pague lo que le es debido. En dicho escrito, señala el nombre con el que se le ha conocido a lo largo de su vida, que no tiene el carácter de oficial, al no ser reconocido por el Estado. No obstante, al no contar dicho ser humano con copia certificada de acta de nacimiento, ni mucho menos con documento de identificación oficial, se le niega la protección de la justicia, al no poder acreditar su interés jurídico como persona.

Existen muchos más supuestos que podrían presentarse, los cuales permiten evidenciar las grandes dificultades que enfrentaría un ser humano cuyo nacimiento no se hubiera registrado en alguna oficialía del Registro Civil, y cómo se atentaría contra su dignidad humana durante el transcurso de su vida.

Sería indudable que la falta del registro de nacimiento de un ser humano lo sitúa en varias situaciones que afectarían su esfera jurídica.

\section{CONCLUSiones}

El derecho no protege a todos los seres humanos nacidos en suelo mexicano, independientemente de que en el texto de las normas positivas vigentes se encuentre señalado que sus derechos humanos deberán respetarse; protege solo a aquellos cuyo nacimiento se haya registrado conforme a los complicados y numerosos requisitos que establecen las leyes de la materia.

El registro de nacimiento es verdaderamente constitutivo de derechos, trámite administrativo sin el cual no es posible acceder al ejercicio de los mismos, ni alcanzar una calidad de vida respetable.

Los procedimientos para el registro y las actas de nacimiento en papel son obsoletas, ya que en la actualidad se le da mayor importancia a un documento que se obtiene en virtud de la realización de un trámite administrativo, que al ser humano mismo. Dichos procedimientos de registro y actas de nacimiento en papel se justificaban en épocas pasadas, pero al contar con la tecnología actual, existe la posibilidad de utilizar otros mecanismos de identificación de los seres humanos, ya que pueden valerse para ello del uso de nuevas tecnologías biométricas, las cuales utilizan bases de datos que detectan el intento de duplicación del registro o de alguna maniobra fraudulenta.
Es importante que un ser humano sea reconocido en la vida jurídica, de modo que esté en capacidad de trascender.

\section{REFERENCIAS}

Acacio Alcides Morales. El cambio de nombre. Revista Jurídica Mario Alario D'Filippo. Disponible en file:///C:/Users/aux2/Downloads/Dialnet-ElCambioDeNombre-4767712\%20 (1).pdf

Andrea Cristina Vera Aldana. LA NiÑEZ y el DeRECHO AL RECONOCIMIENTO DE LA PERSONALIDAD JURÍDICA, Derechos Humanos. (2004). Disponible en http://bibliotecavirtual.clacso.org.ar/Paraguay/cde/20121018 040104/ninez.pdf

Armando F. Portillo González. Omisión del registro del nombre de un niño: otra forma de maltrato infantil. АстА Pediátrica de México 29(5). 2008. Págs. 285-90.

Código Civil del Estado de Querétaro. (México).

Constitución Política de los Estados Unidos MexiCANos [Const]. (México).

Declaración Americana de los Derechos y Deberes DEL HOMBRE DE 1948. Disponible en https://www.oas. org/dil/esp/Declaraci\%C3\%B3n_Americana_de_los_ Derechos_y_Deberes_del_Hombre_1948.pdf

Declaración Universal de los Derechos HumaNOs, 1948. Disponible en http:// www.ohchr.org/EN/ UDHR/Documents/UDHR_Translations/spn.pdf

Decreto por el que se adiciona el Artículo $4^{\circ}$ de la Constitución Política de los Estados Unidos Mexicanos, vigente a partir del 18 de junio de 2014. (Junio 17 de 2014). Diario Oficial de la Federación.

Edgar Morín. La unidualidad del hombre. GAZETA DE ANTROPOLOGÍA. 1997. Disponible en http:/www.ugr. es/ pwlac/G13_01Edgar_Morin.html.

Edmundo Vargas Carreño. El Principio de no IntervenCión y su Vigencia en el Derecho Internacional DEL SIgLO XXI. Instituto de Investigaciones Jurídicas, UNAM. Disponible en http://www.juridicas.unam.mx/ inst/evacad/ eventos/ 2004/0902/mesa3/62s.pdf

Eduardo Gabino Castrejón García. El interés legítimo y jurídico en el sistema de impartición de justicia. AíDA. Ópera Prima de Derecho Administrativo 11. Disponible en http:// historico.juridicas.unam.mx/publica/librev/rev/aida/cont/11/art/art2.pdf

Eleonora Parra de Párraga. La inhumanidad de los derechos humanos. A la saga de los derechos humanos. Razón 
Y PALABRA. Disponible en http://www.razonypalabra. org.mx/N/ N81/M81/03_Parra_M81.pdf

Hans Kelsen. Teoría general Del Derecho y Del EstaDO. UNAM. (1969).

Hegel Cortés Miranda. El Registro Civil a 150 años. BiblioTECA JURÍdicA VirTUAL dEL INSTituto DE INVESTigaCIONES JuRídicas DE LA UNAM. Disponible en http:// archivos.juridicas.unam.mx/www/bjv/libros/7/3067/4. pdf.

Imanol de la Flor. El ACTA DE NACIMIENTO MEXICANA COMO VEHÍCULO PARA EJERCER EL DERECHO A LA EDUCACIÓN; CASO DE LOS HIJOS DE MIGRANTES EN RETORNO. REVISTAS JURÍDICAS, UNAM. Disponible en http://revistas.juridicas.unam.mx/index.php/derecho-internacional/article/view/436/697

INEGI. NATALIDAD. NACIMIENTOS REgISTRADOS POR ENTIDAD FEDERATIVA DE RESIDENCIA HABITUAL DE LA MADRE SEGÚN SEXO, 2012 A 2014. Disponible en http:// www3.inegi.org.mx/sistemas/sisept/Default.aspx?t $=$ mdemo23\&s $=$ est $\& \mathrm{c}=17526$

INEGi. NATALIDAD. NACIMIENTOS REgISTRAdOS SEGÚN SEXO, 1990 A 2014. Disponible en http://www3.inegi.org.mx/sistemas/sisept/Default.aspx?t=mdemo22\&s=es$\mathrm{t} \& \mathrm{c}=17525$

INEGI. NATALIDAD. TASA BRUTA DE NATALIDAD, 1990 A 2015. Disponible en http://www3.inegi.org.mx/sistemas/sisept/Default.aspx? $\mathrm{t}=$ mdemo14\&s $=$ est $\& \mathrm{c}=17533$

Jesús Sotomayor Garza. Deontología DEL ABogado. Editorial Porrúa. (2013).

Joann Novoa. Sin acta de nacimiento, 10 millones de mexicanos. Boletín DE LA CÁMARA DE DIPUTAdOS DE H. CONGRESO DE LA UNIÓN 5199. Mayo 27 del 2012. Disponible en http://www3.diputados.gob.mx/camara/005_comunicacion/a_boletines/2012_2012/005_ mayo/27_27/5199_sin_acta_de_nacimiento_10_millones_de_mexicanos_no_puede_ser_esto_en_pleno_siglo_xxi_diputada_joann_novoa

Karla Cantoral Domínguez. El Derecho a la identidad de un menor: el caso de México. Revista BolivianA DE DEReCHO 20. Julio 2015. Págs. 56-75.

La sombra de Arteaga. Periódico Oficial del Gobierno Del Estado de Querétaro. Tomo Cxlix, N. ${ }^{\circ} 27$. Mayo 13 del 2016.

Ley para la Protección de los Derechos de Niños, Niñas y Adolescentes, 2000. Disponible http://www.gob.mx/cms/ uploads/attachment/file/211050/10_Ley_para_la_Protecci_n_de_los_Derechos_de_Ni_as_Ni_os_y_Adolescentes.pdf
Luigi Ferrajoli. Los FUndAMENTOS DE LOS DERECHOS FUNDAMENTALES. Editorial Trotta. (2001).

Rafael Hernández Marín. Sujetos Jurídicos, Capacidad Jurídica y Personalidad Jurídica. Revista DE FUNDAMENTACIÓN DE LAS INSTITUCIONES JURÍDICAS Y DE DERECHOS HUMANOS 36. 1997.

Raúl G. Koffman. ¿Qué es un ser humano? Revista MÉdica DE Rosario 74. 2008. Págs. 32-34. Disponible en http:// www.circulomedicorosario.org/Upload/Directos/Revista/ 960256Ra\%C3\%BAl\%20Koffman.pdf

Ronald Dworkin. Los DEREChOS EN SERIO. Ariel. (1984).

Secretaría de Desarrollo Social, Subsecretaría de Planeación, Evaluación y Desarrollo Regional. INFORME ANUAL SOBRE LA SITUACIÓN DE POBREZAY REZAGO SOCIAL 2016. Disponible en http://www.gob.mx/cms /uploads/attachment/ file/50347/Quer_taro.pdf

Suprema Corte de Justicia. Primera Sala. Tesis Aislada. Civil CXLII/2007. Registro: 172050. Semanario Judicial de la Federación y su Gaceta, Tomo xxvi. (Julio de 2007).

Suprema Corte de Justicia de la Nación. Primera Sala. Tesis AisladA. 1a . CXVi/2011. Registro 161100. Semanario Judicial de la Federación y su Gaceta. Novena Época, Tomo xxxiv. (Septiembre de 2011).

Tribunales Colegiados de Circuito. Tesis AisladA. Civil I.3o.C.979 C. Registro: 161495. Semanario Judicial de la Federación y su Gaceta, Novena Época, Tomo xxxıv. (Julio de 2011).

Tribunales Colegiados de Circuito. Tesis Aisladd I.4º.A.9.K $\left(10^{\mathrm{a}}\right)$. Semanario Judicial de la Federación y su Gaceta, Registro 2003350, Décima Época, Libro XIX, Tomo 3. (Abril de 2013).

unicef. El Registro de Nacimiento, El Derecho a teNer Derechos. Fondo de las Naciones Unidas de la Infancia, Centro de Investigaciones Innocenti. (2002). Disponible en https://www.unicef-irc.org/publications/ pdf/digest9s.pdf

UNICEF. DERECho A LA IDENTIDAD. LA COBERTURA DEL REGistro DE NACIMIENTO EN MÉxiCO EN 1999 Y 2009. Disponible en http://www.unicef.org/mexico/spanish/ mx_registrodenacimiento(1).pdf

Ximena Urquiaga Medellín. Principio Pro PERsona, MetoDOLOGÍA PARA LA ENSEÑANZA DE LA REFORMA CONSTITUCiOnal. Pág. 20. Disponible en http://www2.scjn. gob.mx/red/coordinacion/archivos_Principio\%20pro\% 20persona.pdf 